\title{
Brain Hamartoma
}

National Cancer Institute

\section{Source}

National Cancer Institute. Brain Hamartoma. NCI Thesaurus. Code C40423.

A hamartoma that occurs in the brain. 